\title{
IMPACTOS SOCIOESPACIAIS DA PRIVATIZAÇÃO DA SEGURANÇA NAS CIDADES AFRICANAS
}

ISABEL MEDEIROS ${ }^{1}$

\begin{abstract}
Resumo - A difusão da privatização da segurança em grande número de cidades africanas é uma realidade relativamente recente, relacionada com o impacto desigual da globalização à escala do continente. A partir de um conjunto de situações particulares (cidades de Maputo, Cabo, Johannesburg, Windhoek, Nairobi, Kano, Lagos, Ibadan e Accra), as quais têm em comum o envolvimento de múltiplos actores e certo grau de informalidade, analisaram-se as diversas iniciativas em curso. Atendeu-se às respectivas motivações e consequências nas práticas espaciais, mas sobretudo nas relações sociais, no dinamismo interno das comunidades e nos elos de ligação entre os cidadãos e o Estado. Nesta perspectiva procurou-se também especificar o papel movediço dos poderes públicos, os desafios colocados à governança, assim como o efeito da privatização da segurança no processo multidimensional de fragmentação urbana.
\end{abstract}

Palavras-chave: Privatização da segurança, África, cidades, governança.

Abstract - SOCIO-SPATIAL IMPACTS OF SECURITY PRIVATIZATION IN AFRICAN CITIES. The diffusion of security privatization in many African cities is still a relatively new reality, following the uneven impact of globalization on a continental scale. Starting from a set of particular situations (cities of Maputo, Cape Town, Johannesburg, Windhoek, Nairobi, Kano, Lagos, Ibadan, Accra), which all have in common the involvement of multiple entities and some informality level, an analysis on the current situation was made. This analysis considered motivations and consequences on special practices, but, mainly, social relations, internal community dynamics and connecting links between citizens and government. In this perspective, we also tried to specify the role of an unstable public power, as well as the security privatization effect on a multidimensional process of urban fragmentation.

Keywords: Security privatization, Africa, cities, governance.

Résumé - A PROPOS DES IMPACTS SOCIO-SPATIAUX DE LA PRIVATISATION DE LA SÉCURITÉ AU SEIN DES VILLES AFRICAINES. La diffusion de la privatisation de la sécurité dans de nombreuses villes d'Afrique est une réalité relativement récente et qui est liée aux répercussions inégales de la mondialisation à l'échelle du continent. À partir d'un ensemble 
de situations particulières (les villes de Maputo, Cabo, Johannesburg, Windhoek, Nairobi, Kano, Lagos, Obadam et Accra), lesquelles ayant en commun l'implication de multiples acteurs et une certaine absence de formalité, on a analysé les diverses initiatives en cours de réalisation. On a considéré les motivations respectives et les conséquences au niveau des pratiques spatiales, mais aussi et surtout au niveau des relations sociales, du dynamisme interne des communautés et des liaisons entre les citoyens et le gouvernement. Dans cette perspective, on a également essayé de spécifier le rôle d'un pouvoir public instable, ainsi que l'effet de la privatisation de la sécurité sur le processus multidimensionnel de la fragmentation urbaine.

Mots-clés: Privatisation de la sécurité, Afrique, villes, gouvernance.

\section{COMO PONTO DE PARTIDA}

No decurso de trabalho de campo realizado ao longo de alguns anos na cidade de Maputo (onde ainda é notória a oposição, todavia já hibridada, entre a área dita de "cimento" e a dos bairros populares/caniços, legado do colonialismo português), depois de deambular pelas suas ruas e de ir ganhando familiaridade com os problemas do quotidiano vivido, chamou-nos a atenção a presença de diversos tipos de intervenções securitárias privadas (para nós já habituais nas cidades da República Sul Africana (RAS) desde o tempo do regime de apartheid, e nas de muitos países da América do Sul), inseridas diferenciadamente na paisagem. A par dos muitos guardas vigilantes, por vezes armados, postados junto dos edifícios ou dormitando numa esquina próxima, das ruas com acesso barrado ou limitado quase sempre por razões 'políticas', destacam-se seguramente pelo impacto espacial os 'conjuntos residenciais fechados' genericamente designados por 'condomínios', termo introduzido na lei 5/91 que não significa strictu sensu um loteamento vedado por razões de segurança, mas reflecte a ideia de copropriedade. Morada de elites locais e de estrangeiros a trabalhar no país, se bem que cada vez mais procurados pelas classes médias emergentes, localizam-se maioritariamente a norte, nas margens do centro da cidade num sector dotado de elevado valor paisagístico - a Costa do Sol. Intercalados com outras edificações, entre as quais 'bolsas' de habitação precária à custa das quais se vão expandindo, dão origem a um tecido urbano heterogéneo, pleno de descontinuidades dado o grande número de espaços intersticiais.

Tratar-se-á de uma moda, consequência da globalização dos modos de vida e das aspirações de certas classes urbanas, ou de uma necessidade real motivada pelo aumento da insegurança?

A realização destes produtos imobiliários traduz um novo modelo de crescimento urbano nas áreas periféricas e semi periféricas da aglomeração, condiciona a produção de espacialidades particulares e demonstra dinâmicas duplas de privatização - do espaço público e da segurança - interligadas com o funcionamento do mercado da construção. Remontando a finais dos anos 80, ocorre numa altura em que, na capital de Moçambique, se fazia sentir grande penúria de alojamentos para albergar cooperantes e técnicos expatriados afluindo ao país e, ao mesmo tempo, se assumia a nível político um conjunto de reformas de natureza económica (no âmbito de programas de ajustamento estrutural), introduzindo profundas rupturas no modelo socialista do pós independência (1975). Progressivamente, por vagas, foram ganhando maior expressão, acompanhando de forma mais ou menos clara a crescente liberalização do mercado (a Lei 5/91 liberalizou o imobiliário mas o solo permanece na posse do Estado) e a abertura ao investimento privado. Importa ter em conta também que as 
iniciativas atrás citadas acontecem num país em que, não obstante a assunção da democracia e da actividade privada, o Estado conserva ainda muitas heranças de centralismo institucional e político; em que não podem ser esquecidas as sequelas de 16 anos de guerra civil (acordos de paz em 1992), com o seu cortejo de deslocados e desmobilizados, muitos dos quais apenas aprenderam a fazer a guerra, de anos de seca ou de inundações devastadoras; em que a pobreza, as assimetrias, a fragmentação social, as tensões intra comunitárias e a criminalidade se têm exacerbado...

Tendo em atenção os factos relatados e o resultado de outras observações efectuadas, em particular sobre o estado de grande carência ou de degradação dos serviços e das infraestruturas públicas em muitos dos bairros percorridos, sobre as profundas diferenças de estatuto e de interpretação das condições de segurança, questionamo-nos sobre as devidas repercussões nas relações sociais, no pulsar da cidade, nas formas de governança, no acentuar da fragmentação urbana. O sentimento da grande ausência ou de ineficácia dos poderes públicos no exercício da justiça, na protecção de todos os cidadãos e na regulação no plano local/ municipal dos sistemas de micro governança securitária, que se esboçam em determinados sectores residenciais, é uma realidade deveras preocupante. Será que a este nível (crucial para a afirmação do Estado) se assiste, como em muitos outros, ao estiolar da respectiva esfera de actuação em favor de actores privados, com os enormes riscos daí decorrentes em matéria de gestão urbana, de respeito pelo ambiente, pelos direitos de cidadania e por princípios democráticos?

Desde há alguns anos que estas temáticas têm suscitado grande atenção no âmbito da comunidade científica sendo já numerosos os estudos relativos a cidades americanas (do norte e do sul), asiáticas e mesmo europeias. Centram-se sobretudo na caracterização dos 'complexos residenciais fechados' (gated communities, nos EUA, security villages, clusters houses, security estates, golf estates na RAS, town houses, secure complex, cluster houses na Namíbia, gated housing estates em Accra, condomínios fechados no Brasil, bairros cerrados ou privados na Argentina, fraccionamientos cerrados no México, compounds na Arábia Saudita...), na análise dos processos da respectiva difusão à escala global e na avaliação crítica das consequências, dos riscos e dos desafios relacionados com a sua progressão. Todavia, poucos são os que se debruçam sobre casos referenciados ao continente africano, onde o fenómeno é ainda relativamente recente atendendo à evolução política e económica dos vários países e às condições da sua inserção nas redes globais. Nos últimos anos, porém, tem-se registado um aumento significativo da investigação sobre o assunto, incidindo sobretudo em cidades integradas no domínio anglófono, com destaque para as da RAS cuja geografia foi modelada por períodos de importante segregação (colonização britânica e depois apartheid de 1948 a 1991). É de salientar o trabalho coordenado por Bénit-Gbaffou et al.(2009), o qual reúne um conjunto alargado de contribuições sobre as problemáticas atrás equacionadas: embora os exemplos sul-africanos sejam preponderantes, abordam-se igualmente outros contextos situados na África Austral - Windhoek e Maputo - na África Ocidental - Lagos, Kano e Ibadan - e na África de leste - Nairobi.

A partir de toda a informação obtida, conjugada com análises de terreno que realizámos em diferentes períodos, foi possível juntar um pequeno número de notas (suportadas numa amostra reduzida de casos impedem quaisquer generalizações), relacionadas com processos originais de privatização do espaço público no domínio da segurança, considerando alguns factores explicativos, especificidades e efeitos no plano urbanístico, social e político. Nesta perspectiva interessou-nos ainda, numa óptica comparativa, reflectir sobre a questão do (dis) funcionamento do Estado nas 'Áfricas', do 'monopólio público' do uso legítimo da violência' 
(concepção 'weberiana' de Estado) e da respectiva legitimação, aqui na sua dimensão urbana e local.

\section{AS ‘ÁFRICAS’ NA CONJUNTURA NEOLIBERAL DOS ANOS 90}

A expansão e multiplicação de diferentes formas de privatização da segurança em muitas cidades africanas advieram, sobretudo, no decurso da década de 90 numa conjuntura de crescente globalização. Dinâmica geradora de profundas mas desiguais transformações de natureza política, social e económica, à escala dos países, inscreve-se no domínio teórico da discussão sobre urbanismo neoliberal, cidade empresarial e neoliberalização das políticas urbanas. Contudo, não se pode subestimar a existência de formas mais antigas de defesa e de protecção, promovidas por particulares ou grupos de residentes, como por exemplo se verificou durante o regime de apartheid na RAS ou na Nigéria, país com um percurso marcado por grande turbulência e por governos militares (Fourchard, 2009).

A forte crise das economias rendeiras e das regulações estatais, esboçada já na segunda metade dos anos 70, deu azo à passagem de um sistema de acumulação fordista a outro de acumulação flexível, em relação com a realização de amplas reformas preconizadas pelas instituições internacionais: haveria que liberalizar as economias e favorecer o aparecimento de outros actores, a fim de estimular o crescimento, contrariando ao máximo a acção directa do Estado (até então fortemente interventor) e de impulsionar paralelamente a democracia participativa. Todas estas circunstâncias tiveram grande eco sobretudo nas cidades capitais onde se registava forte acréscimo demográfico: a crise da dívida externa, interligada com uma profunda crise política, provocou decomposição dos enquadramentos estatais, redução do investimento e consequente deterioração dos equipamentos e serviços públicos, muitos dos quais foram objecto de privatização; mas também agravamento das condições de vida e das desigualdades sociais, grandes disparidades nas oportunidades de acesso a determinados bens e serviços (vão emergindo novas classes ligadas aos negócios, à dinâmica do mercado e ao poder), e crescente descontentamento popular face à inoperância dos governos, factos que criaram sentimentos de revolta, expressos, por vezes, em actos de grande violência. Também o modelo de organização espacial segregado das áreas citadinas, herança do período colonial, o qual foi mesmo reforçado na sequência das independências, embora na base de critérios diferentes (a riqueza e a proximidade do poder), conheceu profundas alterações à escala micro, as quais se sobrepõem ao todo pré existente, sem porém anular a segregação presente: a descentralização da gestão configurou-se como «fundamento de uma nova engenharia política institucional» (Dubresson, Jaglin, 2002: 68); a multiplicação e diversificação dos agentes económicos e sociais, num quadro liberalizado do mercado, entre o qual o do imobiliário, foi acompanhado do aumento e da complexificação da informalidade nas práticas do quotidiano, quer no topo, quer na base da sociedade, configurando-se neste plano como estratégia de sobrevivência e de reprodução social; a instalação ou distribuição de novos empreendimentos, sinalizando realidades importadas, opera-se segundo um padrão aleatório, descurando frequentemente directrizes gerais de planeamento se bem que sancionado pelas autoridades no seio das quais a corrupção se banalizava; o avanço da produção imobiliária em áreas periféricas, para onde os mais pobres eram a pouco e pouco empurrados e confinados em 'ilhas', deu origem à criação de outras 'ilhas', posicionadas na proximidade, «traduzindo uma lógica pontual de produção e apropriação do espaço» (Barata Salgueiro, 1999: 68), onde é chocante a ostentação de riqueza; a falência dos poderes públicos e, em particular, do aparelho policial 
num cenário social fortemente desigual provocou o avolumar da insegurança real, mas também por vezes imaginada, suscitando processos deliberados de segregação voluntária, de corte social e territorial com a envolvente por parte de muitos residentes, sobretudo nos bairros das classes mais abastadas... Tantos aspectos e tantos outros que, em países com democracias jovens em que a insegurança afecta transversalmente a sociedade e a violência constitui um modo de regular as relações sociais muitíssimo assimétricas, tiveram, e têm, significativo impacto espacial e socio-político.

\section{A PROCURA PRIVADA DE SEGURANÇA: MODELOS EM CIRCULAÇÃO MOTIVAÇÕES E PROCESSOS DE PRIVATIZAÇÃO}

Nas cidades africanas a seguir mencionadas identificaram-se diversas modalidades de procura privada de segurança, as quais demonstram sempre, numa dada conjuntura, adaptações, melhor ou pior sucedidas, aos contextos políticos e urbanos locais em que se expressam. A natureza dos processos subjacentes à respectiva difusão revela a junção ou a partilha de influências, complexas e mutantes, de múltiplos agentes, tais como empresas, organizações várias da sociedade civil, mas também por vezes dos poderes públicos.

Em primeiro lugar refiram-se os 'complexos residenciais fechados' (CRF), amplamente generalizados à escala global, como atrás se mencionou. Correspondem a produtos de origem norte-americana, importados como 'boas práticas', cuja divulgação está muito dependente das características locais da estratificação social existente, da dinâmica do mercado fundiário e imobiliário, da actividade dos promotores e das respectivas campanhas de marketing, embora não seja de enjeitar a influência mais ou menos discreta do próprio Estado. $\mathrm{O}$ factor segurança ou, melhor,o sentimento da respectiva falta, aliado ao medo do crime, fenómeno complexo cujas raízes relevam de diversas explicações teóricas, constitui na maior parte dos casos motivação determinante da respectiva procura. Todavia, aquela condição pode combinar-se ou secundarizar-se relativamente a outras, as quais, não sendo específicas das 'Áfricas', adquirem cunho particular no continente: desejo de homogeneização de classe, de formação/invenção de identidades comunitárias forjadas em situação de crise, necessidade de aceder a equipamentos de todo o tipo genericamente em falha no quadro citadino, de fruir qualidade de vida. Por exemplo, no discurso dos promotores e dos habitantes de alguns condomínios de Maputo constata-se, precisamente, a importância dos aspectos atrás citados, relevando-se também a liberdade de movimentos possível, e a partilha de modos de vida de tipo ocidental... O traçado deste quadro indicia bem como o mercado se substitui ao Estado, em particular na oferta de bens básicos a determinados estratos sociais, sobretudo os das novas classes médias em ascensão. Se habitar num condomínio dá e dava em primeiro lugar estatuto, a oferta de dispositivos de segurança já constitui hoje elemento forte de eleição sem que, porém, sublime a afirmação de classe. A realidade apontada leva a concluir que as residências fechadas podem ser vistas como a expressão física da cidade no seio da qual a diferenciação económica e a polarização social são crescentes.

Uma outra iniciativa igualmente resultante da transferência de um modelo internacional (norte-americano) diz respeito aos City Improvement Districts (CID), denominados na terminologia anglo-saxónica Business Improvements Districts (BID). Vulgarizados na RAS, a sua importação mostra um procedimento orquestrado também por actores privados poderosos, não obstante terem sido adoptados pelo sector público no quadro de operações de regeneração urbana em centros históricos declinantes: aqui, nas áreas comerciais, de serviços e de 
lazer comportam uma dimensão de desenvolvimento económico, pois a segurança é entendida como pré condição para garantir investimentos e crescimento. Trata-se de uma forma de auto organização e de autogestão dos bairros, focalizada na prestação de serviços básicos suplementares (entre os quais segurança), financiada pelos proprietários. Se bem que não conduza ao encerramento de um dado perímetro, as lógicas subjacentes são bastante similares às dos CRF: o factor mobilizador continua a ser a procura de segurança embora, de forma análoga, se possa combinar com outros, entre os quais a vontade de criar ou manter coesão social ou territorial. Contudo, singularizam-se porque reflectem o dinamismo de actores de proximidade e assentam num processo mais amplo de gestão do espaço, muitas vezes em parceria com as autoridades (Didier et al, 2009).

Além dos modelos atrás citados interessa ainda referir as enclosures ou road closures, bem representadas por exemplo nalgumas cidades da RAS, em Ibadan e Nairobi, mas com pouquíssima expressão em Maputo, Capetown ou Windhoek: originando o encerramento parcial ou total, permanente ou temporário, de espaços públicos, pressupõem o envolvimento dos cidadãos, de empresas de segurança ou de organizações mistas, os quais assumem o controlo da intervenção. No caso das enclosures, definidas quer em bairros de classes favorecidas quer noutros mais populares, encontram-se algumas características similares às dos CRF; no entanto, o facto de se articularem à escala local, o carácter voluntário da acção na qual prevalece o factor segurança e requer mobilização colectiva, a ocorrência de privatização de facto do espaço público exigindo renegociação constante entre o Estado e os residentes, são alguns aspectos distintivos.

Fourchard (2009), a propósito das cidades do Sudoeste da Nigéria, e muitos outros autores (Olanyi, 2009; Baker, 2002; Anderson, 2002; Agbola, 1997) reconhecem outras formas não estatais aplicadas na prestação de segurança, entre as quais as que designam de vigilantism. Este conceito abarca um conjunto de acções apostadas na manutenção da ordem, na autodefesa e mesmo na autojustiça, protagonizadas por variadíssimas instituições da sociedade civil. Muitas vezes exercidas fora de um quadro legal e jurídico, constituem resposta às limitações da actuação das polícias, sobretudo em bairros desestruturados; espelham assim sentimentos de falta de confiança nos poderes públicos, tal como sucede em certas road closures. Na sua maior parte evoluíram para sistemas tipo community policing (CP), isto é, produção de segurança fundada na cooperação entre residentes e polícia, que emergiu nos Estados Unidos e na Grã-Bretanha a partir dos anos 80, uma forma de governança, dita mais descentralizada e participativa, exportada para as ‘Áfricas' por via da cooperação internacional. Objecto de muitas críticas direccionadas sobretudo para a respectiva falta de adaptação às realidades do continente, salientam-se também os efeitos negativos passíveis de conduzir à rigidificação de divisões sociais, ao reforço do controlo por parte de estados autoritários, às dificuldades em manter uma ordem socio-política estável. Os estudos de caso examinados permitem matizar estas afirmações, se bem que não as contestem totalmente. Nas cidades sul-africanas o CP apoiou-se em estruturas já existentes (Community Policing Foruns); nas da Nigéria, país em que desde 1999 o carácter federal do Estado tem sido alvo de contestação, o CP aplicado ao nível dos estados federados não fez mais do que institucionalizar e generalizar práticas de vigilância já existentes, cujas raízes remontam no tempo e se prendem, em alguns casos, com antigas estruturas associativas tradicionais. A multiplicidade das organizações envolvidas (sistemas de vigilância garantidos pelos habitantes, milícias étnicas, sociedades privadas e grupos religiosos...) alimenta situações de grande turbulência e de confronto entre níveis de Estado. 


\section{SEGURANÇA E PRÁTICAS ESPACIAIS: NOVOS DESAFIOS DE GOVERNANÇA URBANA}

Os impactos provocados nas práticas associadas à produção e reprodução social dos citadinos pelas dinâmicas consideradas são bastante complexos e multidimensionais. O uso do espaço (do bairro, da rua, da residência) deve ser definido não pela sua utilização pelas pessoas mas sim pelas relações e interacções que nele se estabelecem. No que concerne os espaços públicos pode afirmar-se que são suporte privilegiado das redes sociais e das práticas culturais, mas também lugares centrais de integração urbana, especialmente nas cidades africanas. O seu aproveitamento como instrumento securitário foi banalizado e legitimado pela receita global Crime Prevention Trough Environmental Design popularizada por Newman (1972, in Bénit-Gbaffou, et al., 2009: 191). A sua noção de 'espaço defensável', utilizada como princípio de ordenamento urbano na RAS, perdurou depois de décadas de manipulação no quadro político de apartheid: conferindo aos residentes a responsabilidade na guarda do espaço público, propiciou a transformação do mesmo em espaço de grupo, o qual acabou por ser apropriado segundo modalidades frequentemente rotuladas de excessivas e egoístas, gerando mesmo situações de tensão e conflito.

Analisando esta problemática em várias cidades africanas observa-se um rol imenso de consequências, se bem que diferenciadas conforme os contextos: diluição de laços orgânicos entre partes da cidade, atropelos a princípios democráticos, graves e discriminatórias situações de exclusão em relação a populações arbitrariamente julgadas indesejáveis, imposição de temporalidades, desvios desejados ou obrigatórios de certos percursos, criação de 'ilhas' de pobreza justapostas a 'guettos dourados'... Se o impulso da globalização origina potenciais de mobilidade espacial acrescidos e alargamento das redes sociais, gera também grandes contrastes nas respectivas hipóteses de acesso. Num quadro social acentuadamente assimétrico, em que a luta diária pela sobrevivência é quotidiano da maior parte dos habitantes, o medo real ou percepcionado por aqueles que não o partilham, conduz em casos extremos ao encerramento das respectivas práticas sociais no círculo restrito da vizinhança imediata dos domić́lios e num 'arquipélago de espaços seguros' ligados por vias rápidas (modelo da cidade fragmentada de Dear e Flusty, 1998, in Bénit- Gbaffou et al., 2009). Criam-se desta forma autênticos 'muros' físicos e mentais os quais, todavia, não são apenas uma resposta em matéria de segurança: representam também um símbolo de distanciamento entre dois mundos que vivem lado a lado, bem como uma forma de gerir as desigualdades, em particular na regulação do risco, sempre presente, da ocorrência de violência nas interacções sociais. Folio (2007) enfatiza esta ideia para os condomínios da Costa do Sol em Maputo, sublinhando que a privatização da segurança levou à privatização da gestão da disputa em torno dos espaços públicos: as empresas promotoras, para alargarem a área disponível para novos empreendimentos, negoceiam casuisticamente com os moradores dos bairros informais envolventes, o que permite amortecer a insatisfação e a resistência dos mesmos ao desalojamento, enquanto a municipalidade permanece ostensivamente à margem.

Os factos enunciados traduzem o reforço da fragmentação social e a emergência de novas modalidades de governança a interpretar como um modo privado de exercício de poder local e como modelo alternativo de organização territorial. Mas a fragilidade dos equilíbrios entre os diferentes actores envolvidos na micro gestão securitária poderá tornar os fenómenos de exclusão mais frequentes e seguramente mais difíceis de controlar, desvalorizando-se os respectivos custos e comprometendo princípios de justiça social. Neste quadro referencial muitas são as interrogações a colocar relativamente ao papel do Estado 
através das suas diferentes escalas de intervenção (central, municipal, federal...) num sector teoricamente seu monopólio. De acordo com Shearing (1995), o aspecto mais significativo da privatização da segurança seria «a amplitude com a qual as responsabilidades e a autoridade em matéria de governança são transferidas do Estado para entidades privadas no âmbito de um movimento geral da governança em favor da auto-regulação» (Bénit- Gbaffou et al., 2009: 25, adapt.). Será que as diversas 'redes de segurança' em presença atingem ou anulam o poder e os deveres do Estado? Ou, pelo contrário, estará o próprio Estado interessado em favorecê-las desde que, conforme a conjuntura, possa retirar ganhos significativos no plano político e económico, na medida em que reconhece a sua incapacidade no cumprimento de tais funções?

\section{A PRIVATIZAÇÃO DA SEGURANÇA AFECTARÁ O PODER DO ESTADO?}

A associação do crescimento do sector não estatal de prestação de segurança a processos de fragmentação e à diminuição da autoridade do Estado tem alimentado certa polémica. As opiniões dividem-se, embora fundamentadas maioritariamente na análise de dinâmicas em curso nos países do Norte. Ora, as realidades africanas são muito particulares. Está-se perante estados jovens, frágeis e em construção, sensíveis a experiências de governança inéditas, se bem que encarem a segurança como objecto decisivo de luta política; por outro lado, a insegurança vivida no quotidiano por todas as classes sociais não é comparável à que afecta as sociedades dos países do Norte, o que banaliza a formação de 'enclaves' como meio de protecção. Neste plano analítico a consideração da evolução das respectivas atribuições, sobretudo no que concerne a manutenção da ordem e a protecção dos seus cidadãos contra o crime, assim como da sua legitimidade, remete para o assunto largamente discutido do monopólio no uso da violência (mais um mito fundador do que uma realidade), que se cruza com o da natureza do próprio Estado.

Muitos estudiosos encaram a questão enunciada como sinal do fraco poder do Estado, decorrente não só da carência de recursos técnicos e financeiros mas também, muitas vezes, da falta da legitimidade necessária para pretender um monopólio do uso legítimo da violência. Argumentam que a diminuição da confiança das populações na acção da polícia (vista por vezes mais como factor de insegurança do que de protecção), conduz ao desmoronamento do respeito simbólico pelo serviço público: o vazio criado pode assim ser colmatado por diferentes configurações organizativas, as quais canalizam o desencanto popular. Se as actividades desenvolvidas não são controladas, o mais provável é darem azo a sistemas de governança fragmentados, combinando ineficácia e injustiça. Contrapondo-se a esta perspectiva outros autores consideram que o fenómeno em causa não suscita forçosamente o enfraquecimento ou demissão do Estado, mas sim uma alteração no modo de exercer o poder sobre a sociedade, sem abdicar de estar presente num campo tão importante para manter a dominação política na conjuntura flutuante do neoliberalismo e também da democratização. Neste sentido estruturam-se diversas formas de cooperação, de parcerias e de complementaridades com agentes privados, desde que as mesmas permitam continuar a manter influência ou retirar vantagens.

Nos contextos urbanos cuja análise sustenta a presente nota, em que cada caso é um caso, evidencia-se bem a grande diversidade das situações. Praticamente em todos eles é detectável a existência de dinâmicas particulares, desigualmente visíveis, de fragmentação da segurança, que segundo Bénit- Gbaffou et al. (2009: 34) se verificarão «quando as for- 
mas de manutenção da ordem têm ópticas, concepções, objectivos e finalidades diferentes e quando entram em conflito umas com as outras a propósito das normas legais e sociais que veiculam». Olanyi (2009) relativamente a Kano mostra bem os graves efeitos destes processos, resultantes não da oposição entre directivas de actores estatais e não estatais, mas sim do comportamento divergente das polícias ligadas a vários níveis de Estado (Estado de Kano e Estado central), os quais usam milícias como meio de levar a cabo uma luta pelo poder e pela legitimidade política. Também no bairro de Sandton em Johannesburg, habitado por classes abastadas, Dirsuweit (2009) aponta mesmo riscos de secessão política: os moradores, organizados em grupos de pressão, valorizando sentimentos de identidade social, procederam ao encerramento de ruas e arrogam hoje decisões em diferentes domínios de governança.

Se estes exemplos permitem pôr em causa a capacidade interventora do Estado em matéria de segurança, muitos outros há em que se descobrem sinais reveladores de diversas estratégias, encetadas a vários níveis de poder, visando restaurar e reconfigurar a sua influência e autoridade. Na aglomeração do Cabo, através de medidas diversas, entre as quais as de carácter legislativo, tenta-se desacreditar unilateralmente as iniciativas securitárias julgadas não convenientes, encorajando aquelas que actuam no sentido dos objectivos municipais de crescimento económico, como é o caso, por exemplo, de determinados CID de negócios, em que há convergência das políticas neoliberais conduzidas pelo Estado e das estratégias dos agentes privados (Didier et al., 2009). Em Kano, onde se citaram as graves consequências da fragmentação, Olanyi refere, no entanto, que o governo central se tem empenhado, por vários meios, no controlo das acções das milícias, não obstante as muitas dificuldades com que se confronta: a manutenção da ordem apresenta-se como um instrumento de poder para diferentes facções, partidos políticos e níveis de Estado. Também em Maputo são de notar esforços de reafirmação de poder, identificáveis quer a nível central - o Estado surge como agente facilitador não explícito das dinâmicas de privatização da segurança nos condomínios, nos quais se fixam clientelas nacionais e internacionais essenciais para a prossecução do crescimento económico do país - quer a nível local ou municipal, dado que sendo o solo propriedade pública, a especulação imobiliária poderá oferecer largos benefícios.

Em síntese e considerando a grande diversidade das dinâmicas em curso, é extremamente difícil tecer conclusões generalistas. São múltiplos e imbricados os impactos socioespaciais e os factores explicativos das situações estudadas, onde se cruzam, conforme as conjunturas, variados aspectos históricos, políticos e económicos. Se, em muitos casos, a violência social parece constituir factor motivador das intervenções analisadas, será que ao equacionarem-se as causas profundas não se chegará a interligá-las com a 'agressividade' dos processos de urbanização neoliberais, com os impactos sobre os habitantes dos diferentes dispositivos espaciais? Já no que concerne a avaliação da capacidade do Estado em regular as redes securitárias em crescendo, com os riscos apontados decorrentes da sua fragmentação, há que aprofundar a diversidade e as contradições internas às lógicas respectivas, através da articulação de diferentes escalas de governação, diferenciando no plano analítico Estado e poder político, muitas vezes confundido no funcionamento quotidiano daquele. De qualquer forma, está-se perante novos sistemas de governança territorializada, cujas consequências na conjuntura actual são imprevisíveis, se bem que não muito animadoras... 


\section{BIBLIOGRAFIA}

Asiedu A, Arku G (2009) The rise of gated housing estates in Ghana: empirical insights from three communities in Accra metropolis. Journal of Housing and the Built Environment, 24(3): 227-247.

Barata Salgueiro T (1999) Cidade pós moderna. Espaço fragmentado. Inforgeo, 19/20: 225-236.

Bénit- Gbaffou C, Fabiyi S, Peyroux E (éd) (2009) Sécurisation des quartiers et gouvernance locale. Enjeux et défis pour les villes africaines (Afrique du Sud, Kenya, Mozambique, Namibie, Nigeria). Karthala-IFAS, Paris.

Didier S, Peyroux E, Morange M (2009) La diffusion du modèle du City Improvement District (CID) à Johannesburg et au Cap. Régénération urbaine et programme neoliberal en Afrique du Sud. In Bénit-Gbaffou C, Fabiyi S, Peyroux E (éd) (2009) Sécurisation des quartiers et gouvernance locale. Enjeux et défis pour les villes africaines (Afrique du Sud, Kenya, Mozambique, Namibie, Nigeria), Karthala-IFAS, Paris: 85-112.

Dirsuweit T (2009) Les fermetures de rues representent-elles une forme de secession urbaine? Le cas de Sandton, 1994-2001. In Bénit-Gbaffou C, Fabiyi S, Peyroux E (ed) (2009) Sécurisation des quartiers et gouvernance locale. Enjeux et défis pour les villes africaines (Afrique du Sud, Kenya, Mozambique, Namibie, Nigeria). Karthala-IFAS, Paris: 391-414.
Dubresson A, Jaglin S (2002) La gouvernance urbaine en Afrique subsaharienne. Pour une géographie de la régulation. Historiens et Géographes, 379:67-75.

Folio F (2007) Les condomínios à Maputo: enjeux societaux et spatiaux autour de l'implantation des ensembles résidentiels securisés dans la capitale mozambicaine. Annales de Géographie, 655(3):247-270.

Fourchard L (2009) From night guards to ethnic militia groups. The legacy of vigilantism in South of Nigerian Cities. In Bénit-Gbaffou C,Fabiyi S, Peyroux E (éd) (2009) Sécurisation des quartiers et gouvernance locale. Enjeux et défis pour les villes africaines (Afrique du Sud, Kenya, Mozambique, Namibie, Nigeria). Karthala-IFAS, Paris: 323-354.

Lachartre B (2000) Enjeux urbains au Mozambique. De Lourenço Marques à Maputo. Khartala, Paris.

Olaniyi R (2009) Charia, groups d'autodéfense et gouvernement local à Kano (Nigéria): la lutte pour le contrôle social. In Bénit-Gbaffou C, Fabiyi S, Peyroux E (ed) (2009) Sécurisation des quartiers et gouvernance locale. Enjeux et défis pour les villes africaines (Afrique du Sud, Kenya, Mozambique, Namibie, Nigeria). Karthala-IFAS, Paris: 303-322. 